\title{
Síntesis de la jurisprudencia casacional sobre empleo público más significativa del año 2021 (1-11-2020 a 30-11-2021)
}

\author{
Summary of the cassation jurisprudence on Public Employment \\ with higher significance for the year 2021 (2020-11-1 a 2021-11-30) \\ José Ramón Chaves García \\ Ministerio de Justicia (España) \\ ORCID: http://orcid.org/0000-0003-3886-1642 \\ kontencioso@gmail.com
}

\section{NOTA BIOGRÁFICA}

Magistrado especialista de lo contencioso-administrativo en el Tribunal Superior de Justicia en Asturias. Doctor en Derecho y miembro numerario de la Real Academia de Jurisprudencia y Legislación. Ha sido profesor asociado de Derecho comunitario y Director General de Universidades e Investigación del Principado de Asturias.

\author{
Juan José Rastrollo Suárez \\ Universidad de Salamanca (España) \\ ORCID: https://orcid.org/0000-0003-0521-1045 \\ rastrollo@usal.es
}

\section{NOTA BIOGRÁFICA}

Profesor Titular de Universidad de Derecho administrativo en la Universidad de Salamanca. Doctor Europeus en Derecho -Universidad de Salamanca/Universidad de Coimbra (Portugal)- y Premio extraordinario de Grado y Doctorado. Profesor invitado, entre otras, en las Universidades de los Andes y Nariño (Colombia), Andina Simón Bolivar (Ecuador) o James Madison de Virginia (Estados Unidos). Consultor y docente para servidores públicos en distintas instituciones de América Latina (Fundación Salvadoreña para el Desarrollo Económico y Social de El Salvador, Contraloría de Costa Rica, Procuraduría de Paraguay). Miembro de los grupos de investigación State and Nation Making in Latin America and Spain de la Universidad de Princeton (Estados Unidos), Next Generation EU y Grupo de Justicia, Sistema Penal y Criminología de la Universidad de Salamanca e investigador de la Unidad de Investigación Consolidada 302 de la Junta de Castilla y León. Autor de cuatro monografías, más de 25 artículos y más de 15 capítulos de libro en revistas y obras colectivas de Europa y América. Sus principales líneas de investigación son el Derecho urbanístico, la contratación pública y el empleo público y en general la reforma y modernización de la Administración pública en Europa y América Latina. Sus últimas obras son "Crisis, acción y reacción: el teletrabajo en el sector público", Aranzadi, 2021 y "Guía para la planificación gestión y ejecución de los fondos del Plan para la Recuperación Transformación y Resiliencia”, Aranzadi, 2021.

\section{RESUMEN}

A lo largo de la presente sección presentamos una síntesis de la jurisprudencia casacional sobre Empleo Público más significativa del año 2021.

\section{PALABRAS CLAVE}

Jurisprudencia casacional; empleo público; 2021. 
DA. Nueva Época - N. 8, diciembre 2021 - ISSN: 1989-8983 - DOI: https://doi.org/10.24965/da.i8.11029 - [Págs. 170-189]

Sintesis de la jurisprudencia casacional sobre empleo público más significativa del año 2021 (1/11/2020 a 30/11/2021)

José Ramón Chaves García / Juan José Rastrollo Suárez

\begin{abstract}
Throughout the present section, we introduce a summary of cassation jurisprudence on Public Employment with higher significance for the year 2021.
\end{abstract}

\title{
KEYWORDS
}

Cassation jurisprudence; public employment; 2021

\section{SUMARIO}

STS DE 15 DE NOVIEMBRE DE 2021 (REC. 6103/2018) REITERA EL CRITERIO DE LA STS DE 27 DE OCTUBRE DE 2021 (REC. 3598/2018), Y RECUERDA LAS ANTERIORES DE 28 DE MAYO Y 21 DE JULIO DE 2020 (RECS. 5801/2017 Y 102/2018) / STS DE 3 DE NOVIEMBRE DE 2021 (REC. 1280/2020). REITERA LA STS DE 2 DE FEBRERO DE 2021 (REC. 3882/2019) / STS DE 29 DE OCTUBRE DE 2021 (REC. 4697/2020) / STS DE 27 DE OCTUBRE DE 2021 (REC. 3598/2018). SE REITERA LO DICHO EN LA STS DE 26 D SEPTIEMBRE DE 2018 (REC. 1305/2017) STS DEL 25 DE OCTUBRE DE 2021 (REC. 3266/2019). SIGUE LA LÍNEA DE LA STS DE 1 DE OCTUBRE DE 2021 (REC. 3105/2019) / STS DE 29 DE SEPTIEMBRE DE 2021 (REC. 698/2020). REITERA EL CRITERIO SENTADO POR LAS STS DE 20 DE MARZO DE 2018 (REC. 2747/2015) Y 14 DE MARZO DE 2019 (REC. 2717/2016) / STS DE 27 DE SEPTIEMBRE DE 2021 (REC. 4954/2018) / STS DE 24 DE SEPTIEMBRE DE 2021 (REC. 4622/2019) / STS DE 16 DE SEPTIEMBRE DE 2021 (REC. 5828/2019). CITANDO ANTERIOR STS DE 13 DE JULIO DE 2021 (REC. 878/2020) / STS DE 7 DE JULIO DE 2021 (REC. 187/2020). CITANDO ANTERIORES STS DE 18 DE ENERO DE 2021 (REC. 2278/2018) Y STS DE 24 DE JUNIO DE 2021 (REC. 7824/2019) / STS DE 6 DE JULIO DE 2021 (REC. 560/2020). SERÁ SEGUIDA POR LA STS DE 28 DE OCTUBRE DE 2021 (REC. 1478/2020) / STS DE 30 DE JUNIO DE 2021 (REC. 244/2020) / STS DE 29 DE JUNIO DE 2021 (REC. 146/2020) / STS DE 28 DE JUNIO DE 2021 (REC. 8350/2019) / STS DE 24 DE JUNIO DE 2021 (REC. 8335/2019) / STS DE 23 DE JUNIO DE 2021 (REC. 8327/2019) / STS DE 21 DE JUNIO DE 2021(REC. 7173/2019) / STS DE 21 DE JUNIO DE 2021 (REC. 6702/2019) / STS DE 27 DE MAYO DE 2021 (REC. 6186/2019) / STS DE 21 DE MAYO DE 2021 (REC. 5145/2019) / STS DEL 26 DE ABRIL DE 2021 (REC. 4645/2019) / STS DE 26 DE ABRIL DE 2021 (REC. 5378/2019) / STS DE 20 DE ABRIL DE 2021 (REC. 7137/2018). SIGUE LA LÍNEA DE LA STS DE 12 DE ABRIL DE 2021 (REC. 6840/2018), Y SERÁ SEGUIDA POR LA STS DE 31 DE MAYO DE 2021 (REC. 1703/2019) / STS DE 15 DE ABRIL DE 2021 (REC. 4323/2019) / STS DE 12 DE ABRIL DE 2021 (REC. 2305/2019) / STS DE 23 DE FEBRERO DE 2021 (REC. 2495/2019). CON CITA DE LA STS DE 18 DE DICIEMBRE DE 2018 (REC. 3723/2017) / STS DE 22 DE FEBRERO DE 2021 (REC. 2854/2019) / STS DE 10 DE FEBRERO DE 2021 (REC. 2468/2019) / STS DE 25 DE ENERO DE 2021 (REC. 2793/2019) / STS DE 25 DE ENERO DE 2021 (REC. 3135/2019) / STS DE 21 DE ENERO DE 2021 (REC. 1780/2019) / STS DE 20 DE ENERO DE 2021 (REC. 3464/2019) / STS DE 22 DE DICIEMBRE DE 2020 (REC. 2029/2019) / STS DE 17 DE DICIEMBRE DE 2020 (REC. 1078/2019) / STS DEL 17 DE DICIEMBRE DE 2020 (REC. 2167/2019) / STS DEL 16 DE DICIEMBRE DE 2020 (REC. 2308/2019) / STS DEL 16 DE DICIEMBRE DE 2020 (REC. 1812/2019) / STS DE 16 DE DICIEMBRE DE 2020 (REC. 2081/2019). REITERA LA SENTADA POR STS DEL 09 DE DICIEMBRE DE 2020 (REC. 7976/2018) / STS DE 4 DE DICIEMBRE DE 2020 (REC. 5635/2018) / STS DE 3 DE DICIEMBRE DE 2020 (REC. 8124/2018) / STS DE 2 DE DICIEMBRE DE 2021 (REC. 7290/2018). SE INSISTIRÁ EN ESTA LÍNEA CON LA ULTERIOR STS DE 10 DE MAYO DE 2021 (REC. 5877/2018).

\section{STS DE 15 DE NOVIEMBRE DE 2021 (REC. 6103/2018) REITERA EL CRITERIO DE LA STS DE 27 DE OCTUBRE DE 2021 (REC. 3598/2018), Y RECUERDA LAS ANTERIORES DE 28 DE MAYO Y 21 DE JULIO DE 2020 (RECS. 5801/2017 Y 102/2018)}

CUESTIÓN.- Si resulta procedente reconocer en casos de cese del personal interino, una indemnización de 20 días de salario por año de servicio, por entender que se ha producido una utilización fraudulenta. Identificar como normas jurídicas que, en principio, han de ser objeto de interpretación, las contenidas los artículos 10.1.a), 10.3 y 10.5 del Texto refundido de la Ley del Estatuto Básico del Empleado Público (Real Decreto Legislativo 5/2015, de 30 de octubre) y la cláusula 4 del Acuerdo marco de la CES, la UNICE y el CEEP sobre el trabajo de duración determinada (directiva 1999/70/CE del Consejo, de 28 de junio de 1999).

FUNDAMENTO.- El nombramiento del funcionario interino tuvo lugar a consecuencia de una vacante ocasionada por traslado del puesto del titular de la plaza mientras su cese deriva de la externalización 
del servicio prestado. En tal actuación administrativa no se percibe fraude alguno cuya presunción solo por el mero transcurso del tiempo no puede operar sin elemento acreditativo alguno, máxime cuando el cese se produce porque el servicio ha dejado de prestarse -lo que conlleva la amortización de la plaza-y, tal causa de cese derivada de un Acuerdo anterior externalizando el servicio de aguas no fue objeto de impugnación.

DOCTRINA.- El cese de un funcionario interino, con una única relación de servicios, no determina derecho a indemnización de 20 días de año de trabajo desempeñado previsto en la legislación laboral y no en la legislación funcionarial. La legislación española sobre función pública, que no prevé el abono de indemnización alguna a los funcionarios interinos, ni a los funcionarios de carrera cuando se extingue la relación de servicio no se opone a la cláusula 4, apartado 1, del Acuerdo Marco.

\section{STS DE 5 DE NOVIEMBRE DE 2021 (REC. 1456/2020)}

CUESTIÓN.- Determinar si la revocación, figura prevista para actos desfavorables, es el medio adecuado para dejar sin efecto una comisión de servicios, o si al derivarse de ésta efectos favorables para el interesado, procede tramitar el correspondiente procedimiento de revisión de oficio de actos nulos o de declaración de lesividad de actos anulables.

FUNDAMENTO.- La concesión de una comisión de servicios mediante un proceso de selección al que concurren los funcionarios que reúnan los requisitos y deseen obtenerla ha de reputarse un acto con efectos favorables para quien la obtiene. Por tanto, en este caso, para el Sr. Eutimio. Ahora bien, esta circunstancia no determina que hubiera debido seguirse el procedimiento de revisión de oficio para dejarla sin efecto.

No procedía ese camino porque la razón por la que se ha de dejar sin efecto dicha comisión no obedece a una infracción cometida por el Ayuntamiento de Sagunto sino a la falta de veracidad de las manifestaciones del Sr. Eutimio sobre el cumplimiento de un requisito esencial exigido por las bases de la convocatoria para ejercer la función policial. No puede, pues, beneficiarse de su proceder para prolongar su permanencia en una situación contraria al ordenamiento jurídico.

DOCTRINA.- La provisión de puestos de trabajo mediante una comisión de servicio constituye un acto administrativo de provisión temporal urgente y discrecional que exige motivación en su concesión y en su revocación y audiencia del interesado en este último caso.

\section{STS DE 3 DE NOVIEMBRE DE 2021 (REC. 1280/2020). REITERA LA STS DE 2 DE FEBRERO DE 2021 (REC. 3882/2019)}

CUESTIÓN.- Si es posible la baja por enfermedad de los funcionarios que se encuentren en situación administrativa de suspensión de funciones.

FUNDAMENTO.- La situación de incapacidad temporal en la que se enmarca la solicitud de licencia por enfermedad supone el mantenimiento del funcionario en la situación de servicio activo, por lo que es radicalmente contraria a la esencia de la medida de suspensión provisional de funciones que tiene como efecto esencial la de apartar al funcionario de la situación de servicio activo, como medida de protección de los fines de interés público.

DOCTRINA.- No es posible otorgar la licencia por enfermedad al funcionario que se encuentra en situación administrativa de suspensión de funciones, por corresponder a una situación administrativa, la de servicio activo, en la que no se encuentra el funcionario en suspensión de funciones por la aplicación de una medida cautelar en un procedimiento disciplinario.

\section{STS DE 29 DE OCTUBRE DE 2021 (REC. 4697/2020)}

CUESTIÓN.- Si resulta conforme a los principios de igualdad, mérito y capacidad, la revisión general acordada por la Administración, en virtud de la anulación de una base de la convocatoria de un proceso selectivo, que da lugar al reconocimiento del derecho a ser incluidos en la lista de aprobados, a los aspirantes que superen la nota que resulta de ese proceso de revisión y con respeto a los que en la lista inicial habían superado el proceso. 
Segundo.- Como consecuencia de lo anterior, cuando se trata de adjudicar una plaza al aspirante en un proceso selectivo, tras obtener por vía de revisión de actos nulos la posibilidad de superar la fase de oposición y pasar a la fase de méritos, cuál debe ser la nota de referencia que hay que tener en cuenta, si la del último aprobado en su día o la nueva nota que resulta del proceso de revisión, de acuerdo con el número máximo de plazas convocadas y sin perjuicio de terceros de buena fe.

FUNDAMENTO.- La utilización de la nueva nota de corte, tras la revisión de oficio, produce efectos dispares para aspirantes del mismo proceso selectivo que se hallan en la misma situación: unos, los aprobados inicialmente, conservan su nombramiento, otros mantienen el que se les ha reconocido en ejecución de sentencia, otros aprueban ex novo en virtud de la revisión y los hay, como la Sra. Josefa, que hubieran logrado plaza solo unos días antes de resolver la Sala de Discordia, pero ahora no la obtienen.

La Sala aplica la prevalencia del principio de seguridad jurídica del proceso selectivo,y como ninguna solución es buena, solamente cabe aspirar a la que menos se aleje de los principios constitucionales en juego. En concreto, debe mantenerse la nota de corte inicial para no perjudicar a los inicialmente aprobados.

DOCTRINA.- Debemos declarar ahora, en respuesta a la primera de las cuestiones que nos ha sometido el auto de admisión, que la revisión de oficio que pueda emprender la Administración de las bases por la que se rige un proceso selectivo ya realizado y de sus actos de aplicación no puede conducir a resultados contrarios al principio de seguridad jurídica. Y, en contestación a la segunda, procede decir que la nota de corte a aplicar a quienes se encuentren en las circunstancias de la recurrente es la inicialmente fijada.

\section{STS DE 27 DE OCTUBRE DE 2021 (REC. 3598/2018). SE REITERA LO DICHO EN LA STS DE 26 DE SEPTIEMBRE DE 2018 (REC. 1305/2017)}

CUESTIÓN.- Si resulta procedente reconocer en casos de cese del personal interino contratado para la ejecución de programa de carácter temporal, una indemnización de 20 días de salario por año de servicio, por entender que se ha producido una utilización abusiva de las sucesivas prórrogas, más allá del límite legal.

FUNDAMENTO.- Los funcionarios interinos mantuvieron una sola relación de servicios, luego no se trató de «sucesivos contratos o relaciones laborales». En el caso de autos y conforme a los hechos probados, la demandante en la instancia obtuvo un sólo nombramiento para prestar servicios respecto de un sólo Plan cuyo plazo de ejecución se amplió, de ahí que fuese prorrogado su único nombramiento.

DOCTRINA.- El cese de un funcionario interino, con una única relación de servicios, no determina derecho a indemnización de 20 días de año de trabajo desempeñado previsto en la legislación laboral y no en la legislación funcionarial.

\section{STS DEL 25 DE OCTUBRE DE 2021 (REC. 3266/2019). SIGUE LA LÍNEA DE LA STS DE 1 DE OCTUBRE DE 2021 (REC. 3105/2019)}

CUESTIÓN.- En relación a supuesto de abono de complemento de carrera profesional denegado por acto firme. (i) Si es o no necesario seguir los trámites del procedimiento de revisión de oficio de actos nulos en la hipótesis de que exista un acto consentido y firme que pudiera dar lugar a una situación jurídica consolidada, dejados sin efecto a raíz de una infracción jurídica avalada por un pronunciamiento judicial firme; y (ii), en el supuesto de que sea innecesaria dicha acción de nulidad, si el cambio jurisprudencial subsiguiente al reconocimiento de la referida infracción jurídica, ha de producir efectos pro futuro o efectos retroactivos.

FUNDAMENTO.- La Administración ante jurisprudencia declarando la nulidad de actos similares debería acometer la revisión de oficio, pero no puede sortearse la seguridad jurídica y cauce de la revisión de oficio.

DOCTRINA.- A la primera de las preguntas formuladas por el auto de admisión, de acuerdo con lo que se ha dicho antes, hemos de responder que los actos administrativos consentidos, por no haber sido objeto de recurso en el plazo establecido y cuya nulidad de pleno Derecho se afirme, solamente podrán ser removidos mediante el procedimiento de revisión de oficio previsto por el artículo 106 de la Ley 39/2015, de 1 de octubre, del Procedimiento Administrativo Común.

La respuesta a la segunda pregunta ha de ser que los efectos de la declaración de nulidad han de operar desde el momento en que se dictó la resolución que la padece, sin perjuicio de los límites establecidos por la Ley en materia de prescripción de las obligaciones de la Hacienda Pública y de los sentados por el apartado 4 de la disposición derogatoria de la Ley de la Comunidad Autónoma de Castilla-La Mancha 1/2012, de 21 de febrero, de medidas complementarias para la aplicación del Plan de Garantías de Servicios Sociales. 


\section{STS DE 30 DE SEPTIEMBRE DE 2021 (REC. 8223/2019)}

CUESTIÓN: Sobre la participación de funcionarios de libre designación y de designación política en los órganos de selección de los empleados públicos, a los efectos de aplicar la prohibición que prevé el artículo 60.2 del EBEP.

FUNDAMENTO.- No está de más discernir entre la confianza política en la designación de órganos directivos y la confianza que inspira la libre designación mediante convocatoria, como forma que es de provisión de puestos de trabajo. La primera podrá inspirarse prioritariamente en la afinidad política con los titulares de los órganos superiores, sin obviar la capacidad profesional del nombrado; en la segunda el peso de la designación está en la confianza en la idoneidad, capacidad o valía profesional que tiene quien designa en el designado, lo que aprecia libremente, juicio que pondera las cualidades del candidato como funcionario de carrera.

DOCTRINA.- Se declara que respecto de los órganos o comisiones de valoración previstos en el artículo 60 del EBEP, la prohibición de que formen parte de ellos cargos de «elección o de designación política» no alcanza a funcionarios de carrera que ejerzan sus funciones ocupando puestos de libre designación mediante convocatoria pública y así se prevea en las relaciones de puestos de trabajo.

\section{STS DE 29 DE SEPTIEMBRE DE 2021 (REC. 698/2020). REITERA EL CRITERIO SENTADO POR LAS STS DE 20 DE MARZO DE 2018 (REC. 2747/2015) Y 14 DE MARZO DE 2019 (REC. 2717/2016)}

CUESTIÓN.- Si el llamado «premio por jubilación anticipada» constituye una retribución válida de los funcionarios públicos locales.

FUNDAMENTO.- Suponen, pues, una alteración del régimen retributivo de los funcionarios de las Administraciones Locales que carece de cobertura legal y de justificación. Se trata de remuneraciones distintas de las previstas para los funcionarios de las corporaciones locales por la legislación básica del Estado. Se debe reparar en que estos premios no responden a una contingencia o infortunio sobrevenidos, sino que se devengan simplemente por la extinción de la relación de servicio funcionarial cuando se alcanza la edad de la jubilación forzosa o la necesaria para obtener la jubilación anticipada.

DOCTRINA.- El llamado «premio por jubilación anticipada» constituye una retribución de los funcionarios públicos y, por consiguiente, sólo es válido en la medida en que tenga la necesaria cobertura legal.

\section{STS DE 27 DE SEPTIEMBRE DE 2021 (REC. 4954/2018)}

CUESTION.- (i) Si con la entrada en vigor de la Ley de racionalización y sostenibilidad de la Administración Local y, en particular del artículo 92 bis de la Ley de Bases de Régimen Local, queda automáticamente derogado -por antinómico- el Real Decreto 1732/1994, de 29 de julio, sobre provisión de puestos de trabajo reservados a funcionarios de Administración local con habilitación de carácter nacional y, en particular, su Disposición Adicional Tercera; (ii) si, constatada dicha derogación, en su caso, la misma no extiende sus efectos a funcionarios de las Corporaciones que, al amparo de lo dispuesto en la citada Disposición Adicional Tercera del Real Decreto 1732/1994, venían desempeñando las funciones de Tesorero en la fecha de entrada en vigor de la LRSAL.

FUNDAMENTO.- Desde su entrada en vigor por la Ley $27 / 2013$, la regla general consiste en que todos los puestos deben ser cubiertos de forma permanente por funcionarios de la Administración Local con habilitación de carácter nacional, mediante concurso (...). Esta conclusión es la que satisface los intereses de efectividad de la regulación general, pues el régimen transitorio no acogió la pervivencia de situaciones contrarias a la nueva regulación, con la excepción de la ya examinada, y las situaciones de funcionarios como la de la actora, no justifican equiparar aquella regulación excepcional al modelo general de provisión (concurso entre habilitados) de manera que ambos sistemas convivieran, con el resultado de dejar sin aplicación efectiva en determinados puestos y, por ende, en determinadas corporaciones locales, la estructura de control interno introducida por la LRSAL.

DOCTRINA.- Con la entrada en vigor de la Ley $27 / 2013$, de racionalización y sostenibilidad de la Administración Local, y, en particular, del artículo 92 bis LBRL quedó automáticamente derogado por su contradicción con lo previsto en la disposición adicional tercera del Real Decreto 1732/1994, de 29 de julio, sobre provisión de puestos de trabajo reservados a funcionarios de Administración Local con habilitación de carácter nacional. Esta derogación normativa afecta al desempeño de puestos de trabajo reservados a funcionarios de Administración Local con habilitación de carácter nacional, que a la entrada en vigor del nuevo 
artículo 92 bis de la LBRL, se desempeñaban por funcionarios de las corporaciones locales, en virtud de autorización excepcional que permitía dicha disposición adicional tercera del Real Decreto 1732/1994. Estos puestos tenían la condición de vacantes, y tras la entrada en vigor de la Ley 27/2013, de racionalización y sostenibilidad de la Administración Local, debían ser objeto de concurso para su provisión por funcionarios de la Administración local con habilitación nacional en la convocatoria correspondiente.

\section{STS DE 24 DE SEPTIEMBRE DE 2021 (REC. 4622/2019)}

CUESTIÓN.- Determinar si los funcionarios del Cuerpo Nacional de Policía que no presten servicios y/o destinos de uniforme, sino que deban hacerlo obligadamente de paisano, tienen derecho o no a obtener una compensación económica en concepto de gastos de vestuario.

FUNDAMENTO.- No se evidencian razones, ni en las resoluciones administrativas objeto de impugnación ni en la argumentación de la Abogacía del Estado, para que mientras los funcionarios adscritos al servicio de Protección de Personas perciban una indemnización por vestuario, no la reciban los funcionarios integrantes de los otros servicios eximidos reglamentariamente, por razones de seguridad, del uso del uniforme en un Cuerpo que tiene como regla recibir vestuario para realizar su normal función.

DOCTRINA.- La percepción de la indemnización de vestuario a que se refiere el art. 5 del R. D. 950/2005 ... pretende compensar a todos los funcionarios del Cuerpo Nacional de Policía que, por razón de servicio están a obligados a utilizar una vestimenta de paisano acorde con la naturaleza de ese servicio y la entidad de las situaciones y circunstancias que rodean el servicio. Por ello, es absolutamente ajustada a la racionalidad la pretensión ejercitada, quebrantando, en cambio, el principio de igualdad no reconocer el derecho a este complemento a otros funcionarios exentos de la obligación del uso del uniforme por exigencias del servicio que desempeñan.

\section{STS DE 16 DE SEPTIEMBRE DE 2021 (REC. 5828/2019). CITANDO ANTERIOR STS DE 13 DE JULIO DE 2021 (REC. 878/2020)}

CUESTIÓN.- Si existe o no discriminación en el acceso a la carrera profesional en aquellos supuestos en que el personal estatutario eventual del SERMAS resulta excluido de la posibilidad de realizar dicha carrera profesional en relación con el personal estatutario interino.

FUNDAMENTO.- No aporta ningún elemento que diferencie, a los efectos de lo que aquí se discute a eventuales y sustitutos. Sigue haciendo hincapié en que el título que determina el respectivo nombramiento es diferente y que también lo es su régimen, pero no ha indicado ningún rasgo que deba conducir a conclusiones distintas respecto de unos y otros (...). El el distinto e injustificado trato dispensado a una variedad de personal estatutario temporal respecto del personal estatutario fijo, lo cual se hace más claro una vez que se ha reconocido a otro personal estatutario temporal, el interino, el derecho a la carrera profesional, ya que, como se ha explicado, no hay diferencia sustantiva que justifique el distinto trato respecto de la carrera profesional. Y, desde luego, la razón no puede estar en que la negociación colectiva se limitase al personal estatutario fijo e interino, ya que se halla en juego un aspecto importante del régimen jurídico del personal temporal en un contexto normativo en el que, como bien dice la recurrente, la Ley 55/2003, al reconocer en su artículo 40 el derecho a la carrera profesional del personal estatutario, lo predica de todo él, sin distinguir ni excluir a ninguna de sus variedades.

DOCTRINA.- Declarar que es discriminatorio para el personal estatutario temporal eventual y sustituto en las circunstancias expuestas, su exclusión de dicho acceso, frente al personal fijo por no concurrir razones objetivas, en el sentido de la cláusula 4.1 del Acuerdo Marco que acompaña a la Directiva 1999/70/CE, que la justifiquen, como lo pone de manifiesto que se haya reconocido al personal estatutario temporal interino.

\section{STS DE 7 DE JULIO DE 2021 (REC. 187/2020). CITANDO ANTERIORES STS DE 18 DE ENERO DE 2021 (REC. 2278/2018) Y STS DE 24 DE JUNIO DE 2021 (REC. 7824/2019)}

CUESTIÓN.- 1. ${ }^{\text {a }}$ Si la Administración debe responder en vía administrativa de los daños y perjuicios reconocidos en vía penal a favor de miembros de la Policía Nacional cuando el criminalmente responsable es declarado insolvente. 
2. En el caso de que la respuesta a la anterior cuestión fuese afirmativa, determinar si la cantidad que como daños y perjuicios se fijó en la vía penal como indemnización al funcionario de Policía ha de ser reconocida automáticamente también como resarcimiento en la vía administrativa o contencioso-administrativa como ha efectuado la sentencia de instancia.

3. ${ }^{a}$ En el caso de que la respuesta a la anterior fuese negativa, determinación de qué tipos de daños sufridos por los miembros de la Policía Nacional en acto de servicio pueden reputarse antijurídicos a efectos de su resarcimiento por la Administración y cuáles, por el contrario, han de ser soportados por los miembros de la Policía Nacional por razón de su profesión.

FUNDAMENTO.- Es principio centenario de nuestro ordenamiento jurídico la indemnidad de los agentes de los Cuerpos y Fuerzas de Seguridad por los perjuicios que sufran en el desempeño de su función como consecuencia de actuaciones ilícitas de aquéllos sobre quienes la ejercen sin que medie culpa o negligencia por su parte. El derecho a ser resarcidos en virtud de ese principio, explicábamos, es inherente al sentido instrumental de la Administración, ya que quienes la sirven no actúan en interés propio, sino en el público, en el de todos.

DOCTRINA.- Así, en las circunstancias del caso, las lesiones y perjuicios sufridos por los agentes de policía como consecuencia de acciones ilícitas de las personas sobre las que ejercen, sin dolo o negligencia por su parte, las funciones que son propias de su cargo deben ser resarcidos por la Administración, mediante el principio del resarcimiento o de indemnidad, principio general que rige para los empleados públicos. Y, en las circunstancias del caso, la cantidad reconocida con carácter firme en vía penal como resarcimiento es la que debe ser satisfecha como indemnidad.

\section{STS DE 6 DE JULIO DE 2021 (REC. 560/2020). SERÁ SEGUIDA POR LA STS DE 28 DE OCTUBRE DE 2021 (REC. 1478/2020)}

CUESTIÓN.- $1{ }^{a}{ }^{\text {El }}$ alcance del principio de paridad en el acceso a la función pública docente universitaria, desde la perspectiva del artículo 23.2 de la Constitución y del artículo 62.3 de la Ley Orgánica 6/2001, de 21 de diciembre, de Universidades, en relación con la composición de las comisiones calificadoras; $2{ }^{2}$ si el incumplimiento de ese principio puede determinar la nulidad o la anulabilidad del proceso selectivo en su conjunto o de alguno de los actos dictados en el mismo; y $3 .^{\text {a }}$ si el establecimiento de los denominados perfiles en las convocatorias de las plazas docentes universitarias exige una motivación reforzada desde la perspectiva del derecho fundamental de acceso al empleo público.

FUNDAMENTO.- Baste señalar que ese carácter automático en la interpretación de la «composición equilibrada» ha resultado desautorizado por esta Sala, en Sentencia de 29 de septiembre de 2020 (recurso de casación n. ${ }^{\circ}$ 2135/2018), cuando la composición de la comisión había sido mayoritariamente femenina (...). Por otro lado, en la indicada convocatoria, también se establecía el perfil de la plaza convocada, respecto de la cual tampoco se formuló ninguna observación al tiempo de la publicación. Esta circunstancia resulta relevante pues, al margen del alegato general que esgrime contra la previsión de perfiles, las características de la plaza no debieron de parecer tan singulares, como ahora señala, cuando decidió no impugnar esa descripción. (...) las razones que expone el recurrente en esta casación no justifican mínimamente, con la debida concreción y al margen de presunciones o conjeturas, que la caracterización de la plaza convocada que establece el perfil en la convocatoria, y que recogimos en el fundamento primero, tuviera un destinatario único, predeterminado por la propia convocatoria, que pusiera de manifiesto una apariencia solvente sobre la lesión del artículo 23.2 de la CE., atendida su generalidad.

DOCTRINA.- La sentencia es desestimatoria pero implícitamente excluye las cuestiones de legalidad para no confundir el ámbito de la revisión de oficio con el ámbito propio de los recursos ordinarios.

\section{STS DE 30 DE JUNIO DE 2021 (REC. 244/2020)}

CUESTIÓN.- Determinar «la naturaleza jurídica y, en su caso, carácter vinculante de los Principios y Orientaciones para la Aplicación de los Criterios de Evaluación (POACE); si los puntos asignados a cada apartado del baremo deben aplicarse de forma genérica a los cuatro criterios de evaluación o si deben referirse a cada uno de los subapartados de cada criterio y según POACE, motivándose la puntuación que merece cada apartado y subapartado». 
FUNDAMENTO.- Se ha de observar que la motivación ofrecida por la Comisión de Acreditación, más que tener por objeto la explicación de la singular puntuación atribuida a los tres grandes apartados en que se detiene, se dirige a justificar el carácter desfavorable del informe, conclusión a la que ha debido llegar por razones que no expresa, lo cual es algo bien distinto.

Además, dicha explicación se sirve de consideraciones genéricas e imprecisas desde el primer momento.

DOCTRINA.- La reiterada jurisprudencia de la Sala sobre la motivación de las puntuaciones asignadas en los procesos selectivos por los órganos evaluadores. Cuando las disposiciones reguladoras del mismo requieren, como en este caso, condensar el juicio sobre los méritos de los participantes en el procedimiento en términos numéricos y es contestada la puntuación asignada, el órgano evaluador ha de ofrecer las razones que le han llevado a asignar la adjudicada y no cualquier otra. Bastará con referirnos a a las sentencias de la antigua Sección Séptima de esta Sala n. ${ }^{0}$ 1765/2016, de 13 de julio (casación n. ${ }^{\circ}$ 2036/2014) y las citadas en ella, así como a las de esta Sección Cuarta n. ${ }^{\circ}$ 400/2020, de 13 de mayo (recurso n. ${ }^{\circ} 312 / 2018$ ), n. ${ }^{\circ} 412 / 2018$, de 14 de marzo (casación n. ${ }^{\circ}$ 2334/2015), n. ${ }^{\circ}$ 177/2018, de 7 de febrero (casación n. ${ }^{\circ}$ 3024/2015), n. ${ }^{0}$ 1004/2017 (casación n. ${ }^{\circ}$ 2569/2015).

Por lo demás, el proceso de evaluación no puede quedar al margen de las exigencias de publicidad y transparencia que han de informar los procedimientos a fin de hacer patente la objetividad que de la Administración predica el artículo 103 de la Constitución y que el artículo 32 de la Ley Orgánica 6/2001, de 21 de diciembre, de Universidades, impone a la Agencia, las cuales no se compadecen con la inexistencia de acta de la reunión de la Comisión de Acreditación, ni con la falta de constancia de la identidad de quienes asistieron a ella y de los expertos que elaboraron los informes. Hay que recordar que, en lo no previsto por el Real Decreto 1312/2007, su artículo 11, dispone que se habrá de observar lo establecido por el Capítulo II del Título II de la Ley 30/1992, de 26 de noviembre, de Régimen Jurídico de las Administraciones Públicas y del Procedimiento Administrativo Común, hoy artículos 15 y siguientes de la Ley 40/2015, de 1 de octubre, de Régimen Jurídico del Sector Público.

\section{STS DE 29 DE JUNIO DE 2021 (REC. 146/2020)}

CUESTIÓN.- La atinente a si el personal vinculado es tanto personal universitario como personal estatutario o si, por lo contrario, es solamente lo uno o lo otro, y concretamente, si el personal vinculado, aun si se le negara la cualidad de estatutario, puede o no optar a las jefaturas de servicio, de sección o asimiladas de carácter asistencial de las instituciones sanitarias; si ello se limita o no a los hospitales universitarios o cabe en cualquier supuesto, y si para ello es o no necesario que la jefatura en cuestión se halle previamente vinculada conforme al respectivo concierto.

FUNDAMENTO.- La titularidad de una plaza vinculada no implica mutación alguna en la condición funcionarial docente desde la que se desempeña y gracias a la cual se desempeña, sino que es una forma de ejercicio de las atribuciones propias del cuerpo docente de pertenencia. Por tanto, por acceder a una plaza vinculada no se pierde la condición de procedencia -en este caso, pertenencia al cuerpo de catedráticos- ni en él queda suspendida la relación de servicios, y tampoco se adquiere una nueva condición funcionarial, en este caso la de personal estatutario fijo, una de las categorías del universo del llamado personal estatutario del Sistema Nacional de Salud.5. En definitiva, se trata del desempeño de un puesto de trabajo, de ahí que se hable de "plazas vinculadas», no de "personal vinculado», expresión equívoca que llevaría a alumbrar una nueva categoría que engrosaría las ya previstas dentro del personal estatutario, en este caso o asimilada al personal estatutario fijo o como forma de acceso a tal condición (...). $4 .{ }^{\circ}$ La consecuencia es que, en lo funcional y en tanto ocupe una plaza vinculada, ese docente universitario puede ejercer derechos y quedar sujeto a las obligaciones del personal estatutario en tanto preste servicios en una institución sanitaria, lo que tendrá su desarrollo en los aspectos antes mencionados: retributivos, permisos y licencias, sujeción a la potestad de organización o programación, a efectos disciplinarios, etc. y todo conforme a lo convenido entre la Universidad y el respecto Servicio o Institución sanitarias.

$5{ }^{\circ}$ Más en concreto, dentro de esos derechos, el docente universitario que ocupe una plaza vinculada podrá ejercer el de cambio de destino - movilidad-y promoción, pero dentro de su estatus que viene cualificado por la ocupación de plazas vinculadas, sin perjudicar al personal estatutario fijo que ocupe plazas no vinculadas.

DOCTRINA.- $1 .^{\circ} \mathrm{El}$ funcionario docente universitario que ocupe una plaza vinculada no tiene la condición de personal estatutario fijo del artículo 8 del EMPSS, siendo su condición profesional la derivada de la 
pertenencia a un cuerpo docente universitario. Cosa distinta, ajena al pleito, es que un docente universitario adquiera la condición de personal estatutario fijo, o viceversa, lo que plantearía cuestiones de compatibilidad; y también es ajeno al pleito que un facultativo, personal estatutario fijo, sea nombrado profesor asociado.

$2 .^{\circ}$ Un funcionario docente universitario que ocupe una plaza vinculada puede optar a las jefaturas de servicio, de sección o asimiladas de carácter asistencial de las instituciones sanitarias, debiendo estarse a estos efectos a lo acordado en el concierto entre la Universidad y el respectivo servicio de salud, en el que se prevea la relación de puestos asistenciales vinculados y, en su caso, qué jefatura queda vinculada.

2. Respecto de si la posibilidad de ocupar jefaturas se limita sólo a los hospitales universitarios «o cabe en cualquier supuesto», en puridad es una cuestión ajena a este litigio.

\section{STS DE 28 DE JUNIO DE 2021 (REC. 8350/2019)}

CUESTIÓN.- Si la cuantía que perciben los funcionarios del Cuerpo Nacional de Policía por turnicidad ha de considerarse un complemento o una gratificación a efectos retributivos y, por ello, si ha de incluirse, o no, dentro del concepto de "segunda actividad derivada de acto de servicio», de modo que el encontrarse en esta situación no puede suponer una diferencia retributiva de las que con carácter habitual viene percibiendo el funcionario.

FUNDAMENTO.- El complemento por el trabajo a turnos no constituye, a tenor de la descripción que se hace en la resolución impugnada en la instancia, una contraprestación por la prestación de servicios extraordinarios, de carácter eventual, o ajenos a la prestación ordinaria de los servicios propios de la policía. Se trata, por el contrario, de una retribución ordinaria por los servicios que se prestan regularmente, de forma habitual, por aquellos que realizan ese trabajo en la forma de «turnos rotatorios completos», y que perciben el correspondiente complemento todos los meses, periódicamente, salvo el de vacaciones, en el que no se realizan turnos, sencillamente porque no se realiza ninguna prestación.

DOCTRINA.- Cuando el legislador orgánico reconoce que los que lleguen a la situación administrativa de segunda actividad por causa de enfermedad o accidente profesional acaecido en acto de servicio o consecuencia del mismo, deben percibir el cien por cien de las retribuciones que vinieran devengando cuando estaban en la situación administrativa de servicio activo, lo que significa que también han de percibir el complemento por trabajo por turnos que venían realizando de forma habitual, y cuyo abono era fijo en su cuantía y periódico en su devengo, de carácter mensual.

\section{STS DE 24 DE JUNIO DE 2021 (REC. 8335/2019)}

CUESTIÓN.- Si el artículo 47.2 de la Ley de Clases Pasivas puede ser interpretado en el sentido de que el accidente in itinere se debe de considerar como consecuencia del servicio a efectos de percibir pensión extraordinaria por declararse la inutilidad permanente para el servicio.

FUNDAMENTO.- La interpretación que consideramos ajustada al sentido de las palabras utilizadas por el legislador, el contexto normativo en que se encuadra el precepto y la finalidad que persigue, es la defendida por la recurrente. Son dos, en efecto, los supuestos de accidente que en el artículo 47.2 fundamentan la pensión extraordinaria: el que se produce en acto de servicio y el que se produce como consecuencia del mismo.

Este último puede entenderse como el que resulta del acto de servicio, pero también como el que es consecuencia del propio servicio.

DOCTRINA.- El artículo 47.2 del texto refundido de la Ley de Clases Pasivas del Estado, ha de ser entendido en el sentido de que el accidente in itinere producido en el trayecto desde el domicilio y el lugar de trabajo para incorporarse a éste o regresar a aquél es consecuencia del servicio a efectos de percibir la pensión extraordinaria por inutilidad para el servicio.

\section{STS DE 23 DE JUNIO DE 2021 (REC. 8327/2019)}

CUESTIÓN.- Si se ha producido o no, en el caso examinado, una utilización abusiva de los nombramientos de personal estatutario eventual ex artículo 9.3 Estatuto Marco del Personal Estatutario y, en el caso 
de que se constate ese uso abusivo, cuáles deben ser las consecuencias que se anudan en dicha declaración de abuso.

FUNDAMENTO.- Debe garantizarse su estabilidad y el mantenimiento en la relación de servicio hasta su extinción por causa legal o la provisión de la plaza, pero sin aplicación de la condición de indefinido no fijo.

DOCTRINA.- Hemos de reiterar la doctrina jurisprudencial establecida en nuestra sentencia de 26 de septiembre de 2018, cit., declarando que en un caso como el que enjuiciamos, en que se ha producido una utilización abusiva de los nombramientos de personal estatutario eventual ex artículo 9.3 Estatuto Marco del Personal Estatutario la misma solución jurídica aplicable no es la conversión del personal estatutario temporal de carácter eventual de los servicios de salud en personal indefinido no fijo, aplicando de forma analógica la jurisprudencia del orden social, sino, más bien, la subsistencia y continuación de tal relación de empleo, con todos los derechos profesionales y económicos inherentes a ella, hasta que la Administración sanitaria cumpla en debida forma lo que ordena la norma de carácter básico establecida en el art. 9.3, último párrafo, de la Ley 55/2003, de 16 diciembre, del Estatuto Marco del Personal Estatutario de los Servicios de Salud.

\section{STS DE 21 DE JUNIO DE 2021 (REC. 7173/2019)}

CUESTIÓN.- Si cabe inadmitir un recurso contencioso-administrativo por pérdida sobrevenida de su objeto cuando se impugnan las bases de una convocatoria, pero no se impugna -ni se amplía el recurso a ella- la resolución final del concurso.

FUNDAMENTO.- Así no dejaría de ser incoherente que un empleado público impugnase sólo las bases que le impiden concurrir a un proceso selectivo pero no el acto con el que finaliza, y sería incoherente porque cabe presumir que su interés profesional pasa por obtener un beneficio concretado en la obtención de la plaza o evitar una adjudicación indebida. Entenderlo de otra forma implicaría reconocerle un interés próximo, cuando no plenamente identificable, con el mantenimiento abstracto u objetivo de la legalidad, lo que no se admite.

9. Esta no es la situación de un sindicato, cuyos intereses legitimadores son más amplios, identificados con los intereses profesionales de aquellos a quienes representa, lo que se traduce en lo procesal que estén más cerca de pretensiones de mera anulación, no de quién sea el concreto adjudicatario de una plaza. De esta manera no cabe excluir de raíz que permanezca el interés que inicialmente le legitimaba como recurrente para promover la impugnación judicial.

DOCTRINA.- Limitada la pretensión a tal pronunciamiento, sin desplegar efectos prácticos, el interés legitimador del sindicato -como tal- pervive y una eventual sentencia estimatoria serviría de precedente para ulteriores convocatorias.

4. Las dos pretensiones finales -modificar las bases y retrotraer las actuaciones-apuntan al reconocimiento de una situación jurídica individualizada y es respecto de ellas donde con más fundamento podría plantearse que ha perdido su interés legitimador al consentir el acto final que puso fin al procedimiento: si tal acto es firme y consentido y con él se consuma y agota sus efectos el procedimiento, no cabe pretender que se modifiquen las bases y se retrotraiga el procedimiento para que continúe incluyendo a interinos y personal laboral no fijo.

5. En consecuencia, permanece el interés de la recurrente como sindicato para obtener un pronunciamiento de fondo sobre la cuestión litigiosa, y cosa distinta es el juicio que proceda hacer sobre la procedencia de la pretensión expuesta en el anterior punto $2.3 .^{\circ}$ de este Fundamento. Por tanto, se estima el recurso de casación, se casa y anula la sentencia ahora impugnada y se estima el recurso de apelación.

\section{STS DE 21 DE JUNIO DE 2021 (REC. 6702/2019)}

CUESTIÓN.- Si la garantía de reingreso desde servicios especiales al servicio activo opera exclusivamente en el puesto inmediato de reingreso o se extiende también a un segundo puesto de trabajo de libre designación cuando ambos puestos son de adscripción provisional.

FUNDAMENTO.- La garantía de reingreso tiene lugar no solo con ocasión del reingreso, sino para las sucesivas veces mientras no se haya obtenido una adjudicación definitiva, y se extiende también a un segundo puesto de libre designación, 
DOCTRINA.- La garantía de reingreso en los términos del expresado artículo 7 se extiende también a un segundo puesto de libre designación, teniendo en cuenta la forma de acceso y tiempo de ocupación del mismo en este caso, cuando todos los puestos desempeñados han sido mediante adscripción temporal, pues no se cumple el presupuesto de haber obtenido un puesto con carácter definitivo, «en tanto no obtengan otro con carácter definitivo», que permita eludir la aplicación del citado artículo 7.1.

\section{STS DE 27 DE MAYO DE 2021 (REC. 6186/2019)}

CUESTIÓN.- Si procede confirmar o matizar la motivación exigible al cese de un funcionario de carrera en un puesto de libre designación.

FUNDAMENTO.- Se insiste en la línea marcada por la STS de 15 de noviembre de 2019 (rec. 42/2018) rechazando expresiones opacas, estandarizadas, que puedan encubrir una intención patológica por falsa, caprichosa o ajena a los requerimientos del puesto o a las exigencias de idoneidad profesional que llevaron a la elección.

DOCTRINA.- Se ratifica la doctrina sobre exigencia de motivación objetiva, aunque se añade una doble precisión sobre las consecuencias del cese ilegal. Por un lado, que las diferencias retributivas con respecto al puesto perdido deben ser soportadas por el afectado. Y que, no constando ningún vínculo suficientemente estrecho y significativo que justifique que el daño moral que el funcionario cesado dijo haber sufrido, el pronunciamiento puramente declarativo del cese indebido, supone ya una reparación moral del funcionario cesado.

\section{STS DE 21 DE MAYO DE 2021 (REC. 5145/2019)}

CUESTIÓN.- Determinar si cuando se ejecuta una sentencia referida a procesos selectivos y en la que se ordena una nueva baremación de los aspirantes, seguida del nombramiento de quien obtuvo la sentencia favorable, con abono de las retribuciones dejadas de percibir, si las cantidades devengadas generan o no intereses legales y, en su caso, cuál es el dies a quo.

FUNDAMENTO.- En cuanto al devengo de intereses su reconocimiento responde al principio de plena indemnidad y si se opone su iliquidez, esta se predica de la cuantía que deba abonarse al interesado en concepto de principal, no de la incertidumbre sobre si se superará o no el proceso selectivo (...). En consecuencia la incertidumbre es limitada y cabe concluir que de no haberse cometido la infracción habría superado las pruebas como lo demuestra la ejecución de la sentencia, luego habría obtenido plaza junto con el resto de los aspirantes que superaron las pruebas, constituyendo su exclusión el momento en que se puede tener por causado el daño. Y como los derechos económicos se llevan al momento de la toma de posesión dentro del plazo previsto en la convocatoria, ese momento es en el que se ha causado el daño, luego fija el dies a quo a efectos del devengo de intereses que resarce el daño por no percibir las retribuciones en concepto de indemnización.

DOCTRINA.- Al ser nulos de pleno Derecho los actos impugnados, el momento para iniciar el cómputo de los intereses será aquél en que debió percibir sus retribuciones con base en el fin indemnizatorio de los mismos y por el tiempo que estuvo privado de los salarios: a ese momento se retrotraen los efectos y ese es el momento en que se le causó el daño resarcido.

\section{STS DEL 26 DE ABRIL DE 2021 (REC. 4645/2019)}

CUESTIÓN.- Si, en el ámbito de la Administración Pública, el uso de sistemas de videovigilancia, establecidos con carácter permanente y con una finalidad general de vigilancia y seguridad, exige informar a los funcionarios de manera previa, expresa e inequívoca, sobre la finalidad de control de la actividad laboral de dicho sistema y, en su consecuencia, su posible utilización para la imposición de sanciones disciplinarias.

FUNDAMENTO.- El juicio de proporcionalidad se supera porque concurre un objetivo legítimo en el uso de los datos, pues se acredita un incumplimiento reiterado de los deberes propios de un funcionario público con el consiguiente descrédito que se ocasiona a la imagen de la Administración Pública. Teniendo en cuenta que estamos ante una relación de especial sujeción entre el funcionario público y la Administración, y 
que dicha captación de imágenes no se realizó mediante la instalación de cámaras nuevas específicamente instaladas para la funcionaria recurrente, sino que la comisión de la infracción se acredita, entre otros medios, con las cámaras existentes, que ya conocía la recurrente como revela la realización de maniobras que pretenden esquivar el control de las condiciones de trabajo como el horario de cumplimiento diario. Todo ello con una potente presencia del interés general ante este tipo conductas que además de mancillar la imagen de la Administración como organización servicial de la comunidad, su generalización afectaría al adecuado funcionamiento de la institución. De modo que la información ordinaria, por las cámaras instaladas con carácter general en el edificio para la seguridad y vigilancia, también del cumplimiento de las condiciones de trabajo, no alcanza a exigir una concreta y específica previsión sobre el posterior uso a los funcionarios públicos afectado, es decir, sobre la finalidad específica de su utilización, en el caso de eventuales procedimientos disciplinarios.

DOCTRINA.- La fija implícitamente, pese a desestimar el recurso de casación de manera que puede sancionarse al funcionario que conoce la instalación de cámaras de videovigilancia, aunque no hubiere sido advertido que dichas imágenes se podían utilizar en un procedimiento disciplinario.

\section{STS DE 26 DE ABRIL DE 2021 (REC. 5378/2019)}

CUESTIÓN.- Si a falta de regulación expresa respecto de los funcionarios locales, a los efectos del reconocimiento de la compatibilidad conforme al artículo 16.3 de la Ley 53/1984, de 26 de diciembre de incompatibilidades, les son aplicables por analogía las previsiones de la disposición adicional quinta del Real Decreto-Ley 20/2012, de 13 de julio, de medidas para garantizar la estabilidad presupuestaria y de fomento de la competitividad o de la disposición adicional décima de la Ley 2/1987, de 30 de marzo, de la Función Pública de Canarias, sobre adecuación retributiva para la autorización de compatibilidad para actividad privada al personal funcionario de la Administración de la Comunidad Autónoma de Canarias o si, por el contrario, es necesario que el régimen de compatibilidad esté regulado por la administración competente.

FUNDAMENTO.- La previsión de la expresada disposición adicional quinta se ensambla con la previsión del artículo 16.4 de la Ley 53/1984, a la que se encuentra vinculada, que resulta de aplicación supletoria en ese punto, pues no puede reconocerse formalmente el derecho e impedirse materialmente su ejercicio.

DOCTRINA.- La fija implícitamente, pese a desestimar el recurso de casación de manera que aunque no se trate de una norma básica, resultará de aplicación a la función pública local, por su estrecha vinculación con norma básica.

\section{STS DE 20 DE ABRIL DE 2021 (REC. 7137/2018). SIGUE LA LÍNEA DE LA STS DE 12 DE ABRIL DE 2021 (REC. 6840/2018), Y SERÁ SEGUIDA POR LA STS DE 31 DE MAYO DE 2021 (REC. 1703/2019)}

CUESTIÓN.- Determinar cuál es el contenido del deber de motivación exigible en las resoluciones administrativas que acuerdan el cese de funcionarios públicos en puestos de libre designación.

FUNDAMENTO.- No puede aceptarse de ninguna manera una justificación que descansa en hechos que no son ciertos, y lo que ocurre, en realidad, es que en este caso, como dice la Sala de Albacete, el cese no tiene motivación, porque la ofrecida por la Administración, no es cierta porque no hubo la modificación real del puesto del trabajo en que se apoyó el cese, ni se ha intentado acreditar la pérdida de idoneidad de la funcionaria.

De ahí que no pueda afirmarse que la interpretación seguida por la sentencia impugnada convierta una decisión discrecional en otra que no lo es. Mas bien lo que hace es impedir una arbitrariedad, o sea, aplica el principio constitucional de su interdicción, que es un límite al ejercicio de las potestades discrecionales.

DOCTRINA.- El contenido del deber de motivación exigible en las resoluciones administrativas que acuerdan el cese de funcionarios públicos en puestos de libre designación consiste en expresar que las razones de oportunidad basadas en la confianza e idoneidad apreciada para el puesto y que llevaron al nombramiento ya no concurren o, si concurren, qué otra circunstancia objetiva determina la pertinencia del cese, sin que sirvan para ello expresiones opacas, estandarizadas o ajenas a los requerimientos del puesto o a las exigencias de idoneidad profesional que llevaron al nombramiento. 


\section{STS DE 15 DE ABRIL DE 2021 (REC. 4323/2019)}

CUESTIÓN.- 1. Si constituye trato discriminatorio la diferente valoración (respecto de los servicios prestados como personal funcionario o estatutario fijo) de los servicios prestados por el personal funcionario en virtud de un vínculo temporal, (previo como el de interinidad), en un procedimiento de provisión de puestos, en especial en un procedimiento de movilidad interna.2. Si es ajustado a derecho la valoración como méritos de los servicios no sanitarios previamente prestados por los funcionarios que participan en el procedimiento de movilidad interna a plazas en que se prestan servicios sanitarios.

FUNDAMENTO.- el Tribunal de Justicia de la Unión Europea, en su sentencia Rosado Santana (C177/10) de 8 de septiembre de 2011, ha declarado que el mero dato de que los servicios se prestaran en condición de interino no constituye una «razón objetiva» a efectos de la cláusula 4 del Acuerdo Marco; es decir, para que sea legítimo valorar de manera distinta los servicios del personal fijo y del personal interino, debe darse una razón distinta del carácter fijo o interino de quien prestó los servicios (...). Pues bien, si no cabe valorar de manera distinta los servicios previos de los interinos a efectos de la promoción a un cuerpo funcionarial de superior nivel, con más razón no debe caber tampoco para la adjudicación de plazas entre funcionarios de un mismo cuerpo o categoría estatutari.

DOCTRINA.- No puede calificarse de razonable; y, desde luego, no resulta justificable en términos del mérito y capacidad que el art. 103 de la Constitución proclama como principio inspirador en materia de empleo público. Por todo ello, debe concluirse que la valoración de servicios anteriores prestados como personal estatutario fijo en funciones no sanitarias, establecida en el baremo aquí examinado, no es ajustada a Derecho.

\section{STS DE 12 DE ABRIL DE 2021 (REC. 2305/2019)}

CUESTIÓN.- i) La determinación, en procesos de promoción interna vertical, del papel de la negociación colectiva en la materialización de las facultades de autoorganización de la Administración Pública; ii) La determinación y extensión de los requisitos que puede establecer la Administración pública para participar en un proceso de promoción interna vertical y su relación con los derechos constitucionales previstos en los artículos 14 y 23 CE sobre el acceso a los cargos públicos.

FUNDAMENTO.- Las condiciones para el ejercicio del derecho a la carrera profesional en sus distintas modalidades son negociables con los representantes de los funcionarios y esas condiciones son las que constituyen la «determinación concreta» a la que se refiere el artículo 37.1.e) del EBEP.

(...) Tratándose de la promoción interna -y que supone un cambio de cuerpo o escala- esa determinación concreta de las condiciones para su ejercicio, que es lo negociable, debe ajustarse a los límites que prevé el EBEP: que se efectúe mediante un proceso selectivo, que se ajuste a los principios constitucionales de igualdad, mérito y capacidad más los del artículo 55.2 del EBEP (artículo 18.1 del EBEP); que se ostente la titulación exigible para el ingreso al cuerpo o escala al que se promociona y antigüedad de al menos dos años desde el que se promociona. A esos límites se añade lo que prevean las leyes de la Función Pública sobre los sistemas de promoción interna (cfr. artículo 18.2 y 3 del EBEP).

DOCTRINA.- $1 .^{\circ}$ Cada Administración, ejerciendo su potestad de autoorganización, puede negociar la determinación de las condiciones para ordenar los procesos selectivos para la promoción interna vertical mediante los que sus funcionarios ejercitan el derecho individual a la carrera profesional. Tal negociación debe desarrollarse dentro de los límites normativamente exigidos y sobre la base de la normativa que regula y estructura el empleo público.

2. ${ }^{\circ}$ Dentro de las modalidades de ejercicio del derecho a la carrera profesional, si se trata de promoción interna vertical, las pruebas selectivas deben basarse en la idea de cuerpo o escala en cuanto que implica la posibilidad de ascender de los inferiores a los superiores.

$3 .^{\circ}$ Los criterios de admisión a dichas pruebas son los normativamente previstos en el EBEP: exigencias de titulación, antigüedad en el cuerpo o escala de procedencia, más lo que puedan precisar las normas de desarrollo de la legislación básica; y, con arreglo a todo ello, lo que pudiera determinarse mediante negociación, siempre y en todo caso que el proceso selectivo quede sujeto a los principios de igualdad, mérito y capacidad.

4. ${ }^{\circ}$ Dentro de esos límites y ejerciendo las potestades ligadas a la ordenación del empleo público y, dentro del mismo, la gestión del derecho funcionarial a la carrera profesional, cabe diseñar tales procesos 
DA. Nueva Época - N. 8, diciembre 2021 - ISSN: 1989-8983 - DOI: https://doi.org/10.24965/da.i8.11029 - [Págs. 170-189]

Sintesis de la jurisprudencia casacional sobre empleo público más significativa del año 2021 (1/11/2020 a 30/11/2021)

José Ramón Chaves García / Juan José Rastrollo Suárez

selectivos atendiendo a las concretas situaciones de cada Administración y dentro de las mismas, a la de los distintos cuerpos o escalas, pero siempre con respeto a los principios antes citados.

\section{STS DE 23 DE FEBRERO DE 2021 (REC. 2495/2019). CON CITA DE LA STS DE 18 DE DICIEMBRE DE 2018 (REC. 3723/2017)}

CUESTIÓN.- Si la carrera profesional horizontal ha de ser considerada «condiciones de trabajo» a efectos de valorar las diferencias de régimen jurídico aplicables al personal estatutario interino y, en su caso, determinar si existe o no discriminación en aquellos supuestos en que dicho personal quede excluido de la posibilidad de realizar dicha carrera horizontal. Tercero. Identificar como normas jurídicas que, en principio, ha de ser objeto de interpretación, la contenida en los artículos 10 y 70 del Estatuto Básico del Empleado Público, en relación con las cláusulas 2, 3 y 5 de la Directiva 1999/70/CE del Consejo, de 28 de junio de 1999, relativa al Acuerdo marco de la CES, la UNICE y el CEEP sobre el trabajo de duración determinada.

FUNDAMENTO.- La exclusión de los funcionarios interinos y del personal laboral temporal viene esencialmente determinada por la naturaleza temporal de su relación de servicio ya que no se ha discutido la identidad del trabajo realizado por las recurrentes con el de los funcionarios de carrera y el personal laboral fijo. Por tanto, no hay razones objetivas que justifiquen la diferencia de trato pues, como dijimos entonces y debemos reiterar aquí, se apoya en un aspecto que no guarda relación con elementos precisos y concretos que caracterizan la "condición de trabajo» -carrera profesional horizontal- ni resulta indispensable para lograr los objetivos que perseguidos por la Administración balear y tampoco para cumplir con los requisitos generales relativos a los servicios prestados que se valorarán en el diseño de esa carrera profesional.

DOCTRINA.- La carrera profesional horizontal forma parte de las condiciones de trabajo a que se refiere la cláusula $4{ }^{\text {a }}$ del Acuerdo Marco anexo a la Directiva 1999/70/CE y que tiene acceso a ella el personal vinculado a la Administración por tiempo determinado que realiza las mismas funciones que el fijo de categoría comparable.

\section{STS DE 22 DE FEBRERO DE 2021 (REC. 2854/2019)}

CUESTIÓN.- La determinación del plazo máximo para resolver los procedimientos disciplinarios en el ámbito de la función pública autonómica y local en ausencia de una norma con rango de ley que lo establezca de forma expresa.

FUNDAMENTO.- De modo que, con carácter supletorio, y ante la falta de regulación específica al respecto, ya sea por el Estatuto Básico del Empleado Público, o por la Ley 6/1989, de 6 de julio, de la Función Pública Vasca, sobre el procedimiento disciplinario, debe ser de aplicación el expresado Reglamento, que tiene carácter supletorio para los funcionarios de las Administraciones Públicas. Y no el plazo general para resolver del artículo 21.2 de la Ley 39/2015, que postula la parte recurrente.

DOCTRINA.- La fija implícitamente, pese a desestimar el recurso de casación, en cuanto al plazo fijado supletoriamente por el Reglamento estatal de régimen disciplinario.

\section{STS DE 10 DE FEBRERO DE 2021 (REC. 2468/2019)}

CUESTIÓN.- Si las previsiones del artículo 57 de Ley Orgánica 3/2007, de 22 de marzo, para la igualdad efectiva de mujeres y hombres, tienen efecto directo sin mediación de las correspondientes bases de la convocatoria y, en caso afirmativo, si imponen una valoración de la situación administrativa de excedencia voluntaria por cuidado de familiares idéntica a la que se otorga a la situación administrativa de servicio activo.

FUNDAMENTO.- La LO 3/2007, el TREBEP y la Ley autonómica 10/2010, son de superior rango, naturaleza de ley, incluyendo una de naturaleza orgánica, al desarrollar derechos fundamentales, art. $81 \mathrm{CE}$, como es la LO para la igualdad efectiva de mujeres y hombres 3/2007, de 22 de marzo.

Por ello, tiene razón la Sala de instancia cuando arguye que la Orden de 10 de agosto de 1994, debe interpretarse en el contexto legislativo vigente que responde a la realidad social del tiempo en que ha de ser aplicada (art. 3.1 C. Civil). 
Se trata, de que la carrera profesional de las personas que hayan optado por hacer uso de uno de los permisos de protección a la maternidad y de conciliación de la vida personal, familiar y laboral a que se refiere el art. 56 de la LO de Igualdad que incluye el régimen de excedencia, no se vea afectada negativamente por el ejercicio de tal derecho.

DOCTRINA.- Las previsiones del art. 57 de la Ley Orgánica 3/2007, de 22 de marzo, para la igualdad efectiva de mujeres y hombres, tienen efecto directo sin mediación de las correspondientes bases de la convocatoria imponiendo una valoración de la situación administrativa de excedencia voluntaria por cuidado de familiares idéntica a la que se otorga a la situación de servicio activo.

\section{STS DE 25 DE ENERO DE 2021 (REC. 2793/2019)}

CUESTION.- $\mathrm{Si}$, en los municipios de gran población, cuando estamos ante una materia regulada reglamentariamente que venga atribuida a un órgano distinto al pleno, esta atribución competencial persiste o, por el contrario, solamente le corresponde cuanto la regulación se refiera a materias en las que el propio pleno ostente competencias. Precisando más tal cuestión, se plantea si respecto de materias que sean competencia de la Junta de Gobierno Local, este órgano asume también la competencia de su regulación reglamentaria al no tener atribuido el Pleno competencia sobre esas materias; o por el contrario, si el Pleno ejerce su potestad reglamentaria sobre todas las materias, aun cuando la competencia ejecutiva y administrativa sea de los órganos de gobierno, en este caso, de la Junta de Gobierno Local.

FUNDAMENTO.- En el seno de la Administración local sí hay un órgano, el Pleno, que ejerce funciones de «superior control y fiscalización» respecto del «ejecutivo local», esto es, el Alcalde, la Junta de Gobierno Local y demás órganos directivos [artículo 122.4.b) de la LRBRL] y que, además, ejerce poder normativo, esto es, potestad reglamentaria. Esto significa que esa idea de mera aprobación formal de la reforma reglamentaria no puede aceptarse sin más en este ámbito, pues lo pactado o acordado queda abierto a la fiscalización y debate en el Pleno al ejercer la potestad reglamentaria.

DOCTRINA.- En los municipios de gran población, el Pleno configurado como órgano de máxima representación política, debate y control, pero también como órgano administrativo, que ejerce la potestad reglamentaria sobre todas las materias, luego puede regular aquellas cuyo ejercicio es competencia de los órganos ejecutivos, administrativos o de gobierno, en particular la Junta de Gobierno Local.

\section{STS DE 25 DE ENERO DE 2021 (REC. 3135/2019)}

CUESTION.- Respecto del acceso al Cuerpo de Maestros, si el Máster Universitario puede alegarse en la fase de concurso como mérito para acreditar una formación académica evaluable; o, por el contrario, si no cabe porque acredita la formación pedagógica y didáctica necesaria para acceder al Cuerpo de Maestros. En definitiva, a efectos del mérito "formación académica» si cabe aportar titulaciones acreditativas de la formación pedagógica y didáctica y, en su caso, cuáles puedes aportarse.

FUNDAMENTO.- Ese Máster Universitario no puede rechazarse de plano pero tampoco dar lugar a una doble valoración. Por tanto, fuera del acceso al Cuerpo de Profesores, para el acceso a otro Cuerpo docente como es el de Maestros, será ya cometido del correspondiente órgano de selección apreciar -luego valorar- desde su discrecionalidad técnica si ese Máster Universitario aporta al aspirante una mayor formación pedagógica y académica, es decir, un valor añadido respecto de la formación de base que se obtiene con el título de Maestro: en definitiva, una mayor excelencia académica que es lo que valora como mérito en fase de concurso.

DOCTRINA.- El Máster Universitario de Educación Secundaria Obligatoria y Bachillerato, Formación Profesional y Enseñanza de Idiomas no es, por tanto, la titulación exigible para acreditar, en fase de oposición, la formación pedagógica y didáctica para acceder al Cuerpo de Maestros pues esa formación ya se acredita con la titulación exigible para concurrir a esas pruebas selectivas. Como consecuencia de lo anterior, para acceder al Cuerpo de Maestros, el Máster Universitario de Educación Secundaria Obligatoria y Bachillerato, Formación Profesional y Enseñanza de Idiomas puede aportarse en fase de concurso como formación académica para valorar si aporta o no una mayor excelencia o formación pedagógica o didáctica, máxime si se refiere a una especialidad distinta de aquella a la que se concurre en las pruebas de acceso al Cuerpo de Maestros. 


\section{STS DE 21 DE ENERO DE 2021 (REC. 1780/2019)}

CUESTIÓN.- Determinar si es ajustado a derecho la adscripción de un puesto a más de un grupo de clasificación profesional en la relación de puestos de trabajo.

FUNDAMENTO.-La legislación básica en la materia -señaladamente el art. 74 del EBEP- se limita a no prohibir la existencia de «puestos barrados», sin reconocerlos expresamente. De aquí que su argumentación descanse fundamentalmente en la Orden del Ministerio de la Presidencia y de la Secretaría del Gobierno de 7 de febrero de 1989, que sí contempla esa posibilidad de manera explícita. Ahora bien, esta norma reglamentaria debe efectivamente reputarse inaplicable, tal como sostiene la parte recurrida, cuando haya sido aprobada nueva legislación autonómica adaptada al EBEP, tal como establece el último inciso de su disposición final $4 .^{\mathrm{a}}$.

DOCTRINA.- La adscripción de un puesto a más de un grupo de clasificación profesional en la relación de puestos de trabajo no es ajustada a Derecho allí donde lo impida la legislación autonómica sobre función pública posterior al EBEP.

\section{STS DE 20 DE ENERO DE 2021 (REC. 3464/2019)}

CUESTIÓN.- La adecuada interpretación del apartado 1.1.3. en relación con el apartado 1.1 del Anexo I del RD 1364/2010, de 29 de octubre, por el que se regula el concurso de traslados de ámbito estatal entre personal funcionario de los cuerpos docentes contemplados en la LO 2/2003 de 3 de mayo, de educación, en el sentido de si cabe valorar cada uno de los años prestados en el pasado en centros que en su momento tuvieron la calificación de especial dificultad, por no tener tal calificación el puesto actual desde el que se concursa y si, esa misma solución, sería la aplicable cuando el centro desde el que se concursa tuvo esa calificación en el pasado aunque en el momento actual no la ostente.

FUNDAMENTO.- Dado que caben varias interpretaciones igualmente sostenibles entiende que no hay fundamento para desincentivar el trabajo especialmente penoso realizado en el pasado por la sola razón de que el interesado ya no está en esa situación.

DOCTRINA.- El apartado 1.1.3. del Anexo I del Real Decreto 1364/2010 debe interpretarse en el sentido de que los servicios prestados en centros que estuvieron calificados de especial dificultad deben ser valorados, incluso si el centro desde el que se concursa no tiene en ese momento tal calificación.

\section{STS DE 22 DE DICIEMBRE DE 2020 (REC. 2029/2019)}

CUESTIÓN.- Cuál debe ser el contenido del deber de motivación que se deriva de lo dispuesto en el artículo 67 apartado 3 del Texto Refundido de la Ley del Estatuto Básico del Empleado Público y, en particular, si esa motivación puede estar basada en la aportación concreta del funcionario al servicio público prestado y a la consecución de los fines encomendados o habrá de ser necesariamente objetiva, basada estrictamente en causas organizativas o de reestructuración que afecten al servicio público.

FUNDAMENTO.- El artículo 67.3 del Texto Refundido del Estatuto Básico del Empleado Público sólo dispone que «el funcionario pueda solicitar la prolongación», correspondiendo a la Administración competente «resolver de forma motivada la aceptación o denegación de la prolongación». Por tanto, la Administración competente está facultada para apreciar las causas que concurren en cada caso concreto y, conforme a ellas, aceptar o denegar la prolongación, lo que exige necesariamente una motivación adecuada, pero excluye, también, que existan causas tasadas de denegación, como ocurría con la normativa anterior.

En definitiva, la denegación podrá fundarse en cualquier circunstancia que concurra en el supuesto de que se trate, apreciada discrecionalmente por la Administración, si bien, como es lógico, para que no exista arbitrariedad en la decisión, la Administración deberá justificar adecuadamente su actuación (...). En definitiva, es perfectamente válida la ponderación, en la resolución administrativa sobre prolongación en la permanencia de servicio activo, de elementos individualizados basados en el trabajo desempeñado anteriormente por el funcionario solicitante, y que se valore su nivel de adecuación a los estándares de calidad y volumen de trabajo en el respectivo puesto de trabajo, así como si la contribución que pueda realizar a la consecución de los objetivos y metas propios del departamento, tanto en términos de calidad como cuantitativos, resulta positiva para los intereses públicos. 
DOCTRINA.- La motivación de la decisión de la Administración respecto a la solicitud de un funcionario público sobre prolongación de la permanencia en el servicio activo, ex art. 67.3 EBEP, que deberá ajustarse a las previsiones al respecto de las leyes de Función Pública que se dicten en desarrollo del Estatuto Básico del Empleado Público, no está limitada necesariamente a razones de índole estrictamente organizativa, estructural o de planificación de recursos humanos, sino que también puede sustentarse en la valoración de la aportación concreta del funcionario al servicio público prestado y a la consecución de los fines encomendados, debiendo incorporar en todo caso la motivación necesaria.

\section{STS DE 17 DE DICIEMBRE DE 2020 (REC. 1078/2019)}

CUESTIÓN.- Si el requisito de reunir la capacidad funcional al que se refiere el artículo 26.2 de la Ley 55/2003, del Estatuto Marco del Personal Estatutario de los Servicios de Salud, comprende los puestos que se desempeñan con carácter definitivo o también aquellos otros que se desempeñan con carácter provisional.

FUNDAMENTO.- El derecho a la prórroga del servicio activo sólo pueda atender a la capacidad funcional del solicitante en el puesto de nombramiento y no en aquellos que se desempeñan con carácter provisional.

En el caso de autos la Administración actuó en consonancia con la Convención al proceder a adaptar un puesto de trabajo al recurrente que adquirió una discapacidad durante el empleo sin que ese desempeño provisional para atender a su ejercicio del derecho al trabajo pueda equipararse a la capacidad funcional para desarrollar las actividades correspondientes a su nombramiento, ni tampoco a los puestos de trabajo de reserva legal para personas con discapacidad en el momento correspondiente al nombramiento.

DOCTRINA.- El requisito de la capacidad funcional al que se refiere el art.26. 2 de la Ley 55/2003, del Estatuto Marco del Personal Estatutario de los Servicios de Salud comprende solo los puestos que se desempeñan con carácter definitivo, es decir las actividades correspondientes al nombramiento.

\section{STS DEL 17 DE DICIEMBRE DE 2020 (REC. 2167/2019)}

CUESTIÓN.- Si la transformación e integración de una categoría profesional (en este caso la categoría de conductor camillero), en otra categoría profesional (técnico de emergencias sanitarias), para la que se exige una titulación de acceso correspondiente a un subgrupo de clasificación superior, debe comportar, en todo caso, la inclusión en el subgrupo superior según la titulación de acceso exigida en la categoría resultante.

FUNDAMENTO.- Sin que pueda esta Sala pueda pronunciase sobre la legalidad de la norma autonómica que anula la Sala de apelación, pues se trata de una norma autonómica respecto de cuya nulidad, declarada en la sentencia recurrida, no se aduce la lesión de ninguna norma estatal o de Derecho de la Unión Europea (...).

DOCTRINA.- No la fija pero indica como obiter dicta que estas cuestiones relativas al encuadramiento, como fácilmente se colige, hubieran precisado, para su establecimiento y regulación, una norma con rango de ley. De modo que un Real Decreto, como el que ahora se impugna, no puede modificar, ni lo hace, otro Real Decreto para establecer un encuadramiento que no puede ser abordado, insistimos, por una norma que no tiene rango legal.

\section{STS DEL 16 DE DICIEMBRE DE 2020 (REC. 2308/2019)}

CUESTIÓN.- Si la doctrina mantenida por esta Sala en recientes sentencias de 12 de noviembre de 2019 (recurso de casación n. ${ }^{\circ}$ 2618/2017) y de 15 de octubre de 2019 (recurso de casación n. ${ }^{\circ}$ 1899/2017) sobre el reconocimiento de los trienios a quienes han consolidado la última categoría al adquirir la condición de personal estatutario fijo, es extensible o no a quienes aún siguen en promoción interna y no han consolidado la categoría superior.

FUNDAMENTO.- La doctrina jurisprudencial allí establecida no es aplicable ni puede extenderse al caso que enjuiciamos, que presenta un elemento diferencial sustancial, puesto que el recurrente es personal estatutario que, habiendo desempeñado un puesto de superior categoría en provisión temporal, sin embargo 
no ha consolidado el puesto de categoría superior durante cuyo desempeño devengó el trienio que solicita le sea reconocido con la cuantía correspondiente a esa misma categoría, en lugar de a la de su puesto de origen (...) no existe ningún elemento discriminatorio con respecto a personal estatutario fijo en situación comparable.

DOCTRINA.- Los trienios devengados por el personal estatutario fijo en régimen de promoción interna temporal en puesto de categoría superior a la propia de su grupo, si ese personal la adquiere, se calcularán por la cuantía correspondiente a dicha categoría superior a partir del momento de su adquisición y pro futuro, no es extensible al personal estatutario fijo en promoción interna temporal, en la que aún sigue, sin haber consolidado la categoría superior.

\section{STS DEL 16 DE DICIEMBRE DE 2020 (REC. 1812/2019)}

CUESTIÓN.- Si un funcionario docente interino que ha sido cesado el 30 de junio y readmitido al inicio del curso escolar tiene derecho a percibir retribuciones por este periodo cuando (i) ni existe norma, pacto o acuerdo que así lo reconozca, y (ii) ha aceptado el cese por no haberlo recurrido en tiempo y forma.

FUNDAMENTO.- El cese de los funcionarios interinos, también el de la actora, responde a la finalización de la causa que motivó cada uno de sus nombramientos como funcionaria interina, siendo tal causa objetiva la finalización del respectivo período lectivo del curso escolar, que se produjo el 30 de junio de cada uno de los años que se indica en la reclamación, y sobre la base de una configuración previa de la relación jurídica de servicio de tiempo determinado, que tuvo en cuenta de manera predeterminada el efecto extintivo de la finalización del periodo lectivo (...). Lo relevante es que la relación de servicio había sido extinguida válidamente al final del periodo lectivo de cada curso escolar, sobre la base de razones objetivas y predeterminadas. Por consiguiente, reconocer como hace la sentencia recurrida, el devengo de retribuciones sin que traiga causa de una relación de servicio existente, dada la extinción legítima y además consentida de las sucesivas relaciones de servicio de duración determinada, supone una vulneración frontal de lo dispuesto en el art. 14.d) y del art. 10.3 y 5, del Real Decreto Legislativo 5/2015, de 30 de octubre, por el que se aprueba el texto refundido de la Ley del Estatuto Básico del Empleado Público, así como una infracción de la doctrina jurisprudencial establecida respecto a la interpretación del alcance de la Cláusula 4 del Acuerdo Marco sobre el trabajo de duración determinada que figura en el Anexo de la Directiva 1999/70/CE.

DOCTRINA.- La finalización del vínculo de relación de servicio se produce en las respectivas fechas de los ceses del personal funcionario interino -que en este caso fue a 30 de junio de cada uno de los años reclamados-, y la iniciación de un nueva relación de servicio al inicio del siguiente curso escolar no invalida los efectos jurídicos de cada uno de los ceses precedentes, $y$, por ende, no otorga derecho alguno al funcionario interino en esta situación para percibir retribuciones por el periodo de tiempo transcurrido entre el cese anterior y el inicio de una nueva relación de servicio, como tampoco otorga derecho al reconocimiento de otros efectos de índole administrativa, como antigüedad o cómputo de servicios prestados, en relación al indicado periodo.

\section{STS DE 16 DE DICIEMBRE DE 2020 (REC. 2081/2019). REITERA LA SENTADA POR STS DEL 09 DE DICIEMBRE DE 2020 (REC. 7976/2018)}

CUESTIÓN.- Si se ha producido o no, en el caso examinado, una utilización abusiva de los nombramientos de personal estatutario eventual ex artículo 9.3 Estatuto Marco del Personal Estatutario y, en el caso de que se constate ese uso abusivo, cuáles deben ser las consecuencias que se anudan en dicha declaración de abuso.

FUNDAMENTO.- Constatada la utilización abusiva de los nombramientos de personal estatutario eventual ex artículo 9.3 EBEP, con vulneración de lo dispuesto en la cláusula 5.1 del Acuerdo Marco incorporado a la Directiva 1999/70, la solución jurídica aplicable no es la conversión del personal estatutario temporal de carácter eventual de los servicios de salud en personal indefinido no fijo, aplicando de forma analógica la jurisprudencia del orden social, sino, más bien, la subsistencia y continuación de tal relación de empleo, con todos los derechos profesionales y económicos inherentes a ella, hasta que la Administración sanitaria cumpla en debida forma lo que ordena la norma de carácter básico establecida en el art. 9.3, último párrafo, de la Ley 55/2003, de 16 diciembre, del Estatuto Marco del Personal Estatutario de los Servicios de Salud. 
Esta solución es la más acorde con las exigencias de una planificación adecuada de los recursos públicos en los servicios de salud, bajo los principios de buena administración que vinculan a la Administración (art. 103.1 CE), ya que corresponde a la Administración titular del servicio determinar, tras los estudios correspondientes, si procede o no la creación de una plaza estructural, con las consecuencias ligadas a su decisión. La jurisprudencia de nuestra Sala ha rechazado reiteradamente la aplicabilidad de la figura de personal indefinido no fijo como solución para los supuestos de utilización sucesiva por las Administraciones Públicas de contratos o nombramientos de carácter temporal para atender necesidades permanentes o de carácter estructural. Igualmente, ha considerado esa jurisprudencia que no procede reconocer al personal nombrado por tiempo determinado en las condiciones que se acaban de mencionar el derecho a ser indemnizado por su cese cuando este se acuerde por la Administración.

La declaración de la plaza ocupada por el actor como estructural es un pronunciamiento que excede del ámbito de las medidas adecuadas para prevenir el abuso de la contratación temporal, máxime ante el hecho admitido y constatado en la sentencia recurrida de que la Administración recurrente ha acometido, a través del plan de estabilidad del empleo y provisión de plazas de personal estatutario del Servicio Gallego de Salud 2017-2018, la consolidación de determinadas plazas como la ocupada por el actor, con aplicación, por tanto, de la solución prevista en el artículo 9.3 de la Ley 55/2003.

DOCTRINA.- En un caso como el que enjuiciamos, en que se ha producido una utilización abusiva de los nombramientos de personal estatutario eventual ex artículo 9.3 Estatuto Marco del Personal Estatutario la misma solución jurídica aplicable no es la conversión del personal estatutario temporal de carácter eventual de los servicios de salud en personal indefinido no fijo, aplicando de forma analógica la jurisprudencia del orden social, sino, más bien, la subsistencia y continuación de tal relación de empleo, con todos los derechos profesionales y económicos inherentes a ella, hasta que la Administración sanitaria cumpla en debida forma lo que ordena la norma de carácter básico establecida en el art. 9.3, último párrafo, de la Ley 55/2003, de 16 diciembre, del Estatuto Marco del Personal Estatutario de los Servicios de Salud.

\section{STS DE 4 DE DICIEMBRE DE 2020 (REC. 5635/2018)}

CUESTIÓN.- Si para el ingreso por el sistema general de acceso libre en la Escala de Técnicos Facultativos Superiores de Organismos Autónomos del Ministerio de Fomento, es bastante estar en posesión o cumplir los requisitos necesarios para obtener el Título de Doctor, Licenciado, Ingeniero, Arquitecto o Grado a la fecha de finalización del plazo de presentación de instancias, o si es necesario el Máster que habilite para el ejercicio de la profesión regulada de Ingeniero de Caminos, Canales y Puertos.

Y los preceptos cuya interpretación nos pide son el artículo 76 del Estatuto Básico del Empleado Público en relación con las disposiciones Adicionales octava y novena de la Ley 30/1984 y el Real Decreto 1837/2008, de 8 de noviembre.

FUNDAMENTO.- En definitiva, no parece haber duda de que el ejercicio de la profesión regulada de ingeniero industrial requiere, conforme a las determinaciones del Derecho de la Unión Europea, una titulación que no se corresponde con la de grado.

DOCTRINA.- Para el ingreso por el sistema general de acceso libre en la Escala de Técnicos Facultativos Superiores de Organismos Autónomos del Ministerio de Fomento, es necesario el Máster que habilite para el ejercicio de la profesión regulada de Ingeniero de Caminos, Canales y Puertos.

\section{STS DE 3 DE DICIEMBRE DE 2020 (REC. 8124/2018)}

CUESTIÓN.- i) Qué retribuciones -básicas y complementarias- han de percibir los miembros de la Guardia Civil en caso de que padezcan incapacidad temporal para el servicio; y ii) en particular, si dichas retribuciones se rigen por lo establecido en las disposición adicional sexta del Real Decreto-Ley 20/2012, de 13 de julio, de medidas para garantizar la estabilidad presupuestaria y de fomento de la competitividad, o bien si dicha norma no desplaza -sino que complementa- lo dispuesto en los artículos 20 y 21 del Real Decreto Legislativo 4/2000, de 23 de junio, por el que se aprueba el texto refundido de la Ley sobre Seguridad Social de los Funcionarios Civiles del Estado, así como lo establecido en el artículo 21 del Real Decreto Legislativo 1/2000, de 9 de junio, por el que se aprueba el texto refundido de la Ley sobre Seguridad Social de las Fuerzas Armadas. 
FUNDAMENTO.- En base a doctrina anterior, por todas la STS de 22 de octubre de 2019 (rec. 2005/2017) la limitación retributiva se mantiene a partir del cuarto mes.

DOCTRINA.- Primero. Antes de la entrada en vigor de la Ley 29/2014, de 28 de noviembre, del Régimen del Personal de la Guardia Civil, el número 2, párrafo primero, inciso final de la Disposición adicional sexta del Real Decreto-ley n. ${ }^{\circ}$ 20/2012, de 13 de julio, debía interpretarse en el sentido de que lo previsto en tal inciso no tenía más límite temporal que el de la subsistencia misma de la situación de incapacidad temporal. Segundo. Después de esa entrada en vigor, ha de interpretarse en el sentido de que lo previsto en él ha de tenerse por finalizado si, a la fecha de tal entrada en vigor, ya hubieran transcurrido cuatro meses, contados desde el inicio de la insuficiencia temporal de condiciones psicofísicas para el servicio.

\section{STS DE 2 DE DICIEMBRE DE 2021 (REC. 7290/2018). SE INSISTIRÁ EN ESTA LÍNEA CON LA ULTERIOR STS DE 10 DE MAYO DE 2021 (REC. 5877/2018)}

CUESTIÓN.- Si el plazo máximo de seis meses de suspensión provisional de funciones que puede adoptarse como medida cautelar en la tramitación de un expediente disciplinario, según dispone el artículo 98.3 de la Ley del Estatuto Básico del Empleado Público, aprobado por el Real Decreto Legislativo 5/2015, de 30 de octubre, resulta también de aplicación durante la sustanciación de un procedimiento judicial penal, o si, por el contrario, la suspensión provisional acordada por la Administración se mantendrá por el tiempo a que se extienda la prisión provisional u otras medidas decretadas por el Juez y que determinen la imposibilidad de desempeñar el puesto de trabajo.

FUNDAMENTO.- Aunque los hechos pudieran tener relación con el ámbito del puesto de trabajo del funcionario público y, por tanto, ser susceptible de procedimiento disciplinario, éste habrá de quedar en suspenso al tener carácter preferente el procedimiento penal (art. 94.3 del EBEP), de manera que, en esta situación, la Administración pública no tiene el control de la duración del procedimiento, por lo que no existe el vínculo entre plazo máximo del procedimiento disciplinario, y la duración limitada de la medida provisional de suspensión de funciones.

DOCTRINA.- En un caso como el que enjuiciamos, en que se imputan a un funcionario público hechos constitutivos de delito que, por estar relacionados con el ámbito de su cometido como empleado público, también pueden integrar una infracción disciplinaria, la Administración habrá de adoptar la medida cautelar de suspensión durante todo el tiempo que dure la medida cautelar judicial de prisión provisional, u otra que impida el desempeño de puesto de trabajo por el funcionario público sometido al procedimiento penal, y podrá adoptar la suspensión durante el curso del procedimiento penal, sin que la medida quede sujeta a la limitación temporal de seis meses ni vinculada a la medida de prisión provisional u otras medidas cautelares del procedimiento penal, por lo que la suspensión provisional de funciones podrá mantenerse durante el procedimiento penal, siempre que ello se motive debidamente y resulte proporcionado para la salvaguarda de los intereses públicos. 